\title{
Tree growth and its climate signal along latitudinal and altitudinal gradients: comparison of tree rings between Finland and the Tibetan Plateau
}

\author{
Lixin Lyu ${ }^{1}$, Susanne Suvanto ${ }^{2}$, Pekka Nöjd ${ }^{2}$, Helena M. Henttonen ${ }^{3}$, Harri Mäkinen ${ }^{2}$, and Qi-Bin Zhang ${ }^{1}$ \\ ${ }^{1}$ State Key Laboratory of Vegetation and Environmental Change, Institute of Botany, Chinese Academy of Sciences, \\ Beijing, 100093, China \\ ${ }^{2}$ Natural Resources Institute Finland, Bio-Based Business and Industry, c/o Aalto University, P.O. Box 16200, \\ 00076 Espoo, Finland \\ ${ }^{3}$ Natural Resources Institute Finland, Economics and Society, P.O. Box 2, 00791 Helsinki, Finland \\ Correspondence to: Lixin Lyu (lixinlv@ibcas.ac.cn)
}

Received: 26 December 2016 - Discussion started: 6 January 2017

Revised: 14 May 2017 - Accepted: 22 May 2017 - Published: 23 June 2017

\begin{abstract}
Latitudinal and altitudinal gradients can be utilized to forecast the impact of climate change on forests. To improve the understanding of how these gradients impact forest dynamics, we tested two hypotheses: (1) the change of the tree growth-climate relationship is similar along both latitudinal and altitudinal gradients, and (2) the time periods during which climate affects growth the most occur later towards higher latitudes and altitudes. To address this, we utilized tree-ring data from a latitudinal gradient in Finland and from two altitudinal gradients on the Tibetan Plateau. We analysed the latitudinal and altitudinal growth patterns in tree rings and investigated the growth-climate relationship of trees by correlating ring-width index chronologies with climate variables, calculating with flexible time windows, and using daily-resolution climate data. High latitude and altitude plots showed higher correlations between tree-ring chronologies and growing season temperature. However, the effects of winter temperature showed contrasting patterns for the gradients. The timing of the highest correlation with temperatures during the growing season at southern sites was approximately 1 month ahead of that at northern sites in the latitudinal gradient. In one out of two altitudinal gradients, the timing for the strongest negative correlation with temperature at low-altitude sites was ahead of treeline sites during the growing season, possibly due to differences in moisture limitation. Mean values and the standard deviation of treering width increased with increasing mean July temperatures on both types of gradients. Our results showed similarities
\end{abstract}

of tree growth responses to increasing seasonal temperature between latitudinal and altitudinal gradients. However, differences in climate-growth relationships were also found between gradients due to differences in other factors such as moisture conditions. Changes in the timing of the most critical climate variables demonstrated the necessity for the use of daily-resolution climate data in environmental gradient studies.

\section{Introduction}

Understanding how tree growth responds to temperature changes is crucial for an accurate prediction of future changes in forest dynamics caused by continuing global warming. Since both altitudinal and latitudinal gradients are associated with consistent temperature differences, both can serve as potential natural laboratories to infer forest responses to global warming (Jump et al., 2009; Stevens, 1992; Blois et al., 2013). A temperature decline of approximately 5 to $6.5^{\circ} \mathrm{C}$ per $\mathrm{km}$ of elevation on an altitudinal gradient corresponds to moving approximately $1000 \mathrm{~km}$ poleward on a latitudinal gradient (Jump et al., 2009).

Tree growth responds to temperature changes along latitudinal gradients that correspond to changes along altitudinal gradients in mountainous areas. Towards the cold end of the gradients, low temperature limits tree growth and ultimately prevents the growth, reproduction, or survival of trees 
at the treeline (Henttonen et al., 1986; Körner, 1998; Jobbágy and Jackson, 2000; Lyu et al., 2016b). In contrast, at lowlatitude or low-altitude areas, competition and drought are typical factors that limit tree growth and recruitment (Loehle, 1998; Mäkinen et al., 2003; Lv and Zhang, 2012; Di Filippo et al., 2007; Loehle et al., 2016). In regions with annual or seasonal water deficits, higher temperatures would increase the evapotranspiration, thus increasing drought stress on tree growth (Fan et al., 2013). Therefore, in such environments, tree growth is typically negatively correlated with temperature and positively correlated with precipitation. For instance, Mäkinen et al. (2003) reported a correlation between the radial increment of Picea abies (L.) Karst and the summer temperature changes from positive near the Arctic Circle to negative within central Europe. Similarly, using a multi-species data set from the International Tree-Ring Data Bank, Wettstein et al. (2011) showed that high-latitude ringwidth series were more likely to positively correlate with summer temperatures, while low-latitude sites commonly showed negative correlation. Similar correlation patterns between ring-width series and summer temperatures have been reported on altitudinal gradients; examples can be found in Andreassen et al. (2006) for P. abies and Shen et al. (2016) for Larix olgensis A. Henry.

In addition to the gradually changing relationship between temperature and growth, the timing of radial increment shifts along the latitudinal and altitudinal gradients exerts a further influence on the spatial patterns of tree growth (Henttonen et al., 2009; Jyske et al., 2014). The period of cambial activity and xylem cell growth gradually shortens towards colder areas due to thermal limits in wood formation (Rossi et al., 2007). As the timing of growth changes, the time window, in which climate conditions affect growth, changes most with increasing latitude (Henttonen et al., 2014).

Studies on climate-growth relationships are typically based on monthly average values of climate variables (Briffa et al., 2002; Mäkinen et al., 2002; Andreassen et al., 2006). Since time periods that influence tree growth may not correspond to calendar months, information about climatic effects on tree growth will potentially be lost if monthly averages were used (Hordo et al., 2011; Korpela et al., 2011; Henttonen et al., 2014). To better understand the climatic drivers of tree growth, higher-resolution climate data and more flexible time frames should therefore be utilized (Kim and Siccama, 1987; Vaganov et al., 1999; Henttonen et al., 2014). In studies along temperature gradients (such as altitudinal and latitudinal gradients), this may be even more critical because the calendar month time window may better suit some parts of the temperature gradient than others and therefore the detected gradient patterns might partly be artefacts of the time windows that were utilized.

In this study, we examined annual ring widths and their climatic signals along two types of temperature gradients using daily-resolution climate data: one latitudinal gradient in Finland and two altitudinal gradients on the Tibetan Plateau. Our starting hypotheses were that (1) the change of the growthclimate relationship is similar along both latitudinal and altitudinal gradients, and (2) the time periods during which climate maximally affects radial growth occur later towards higher latitudes and altitudes; consequently, the use of daily climate data instead of monthly averages will reveal more detailed climatic signals of tree growth.

\section{Materials and methods}

\subsection{The Finnish sites}

In Finland, study sites were selected across a gradient of more than $850 \mathrm{~km}$ from southern Finland to the northern timberline of $P$. abies in Lapland (Fig. 1). A total of 48 pure $P$. abies stands were sampled in both national parks and private forests without visible logging activities (Table 1). All plots were on mineral soil, which is typical for P. abies in the study area. All sampling sites represent rather similar altitudes ( $115 \mathrm{~m}$ in southern Finland and up to $410 \mathrm{~m}$ in northern Finland). On each plot, 15 dominant trees without visible damage were cored at breast height $(1.3 \mathrm{~m})$. The number of sample trees was lower in some cases due to a limited number of healthy dominant trees that were available (Table 1). The method of sampling and measurement of the data set are described in detail in Mäkinen et al. (2000) for sites 1-40 and in Mäkinen et al. (2001) for sites 41-48.

\subsection{The Tibetan Plateau sites}

The data from altitudinal gradients on the Tibetan Plateau consisted of two gradients. The first gradient was sampled in summer 2007 and consisted of four Abies spectabilis (D. Don) Spach plots on the south-central Tibetan Plateau (SCTP), ranging from the lower $(3410 \mathrm{~m})$ to the upper limit (3920 m) of this A. spectabilis forest (Fig. 1, Table 1). The plots were subjectively located to represent spots regarding topography and stand structure at each altitude level. The plots extended $60 \mathrm{~m}$ along the slope and $30 \mathrm{~m}$ along the contour line. All trees with at least $10 \mathrm{~cm}$ diameter at breast height (corresponding to a height of $1.3 \mathrm{~m}$ ) were cored. The data are described in detail by Lv and Zhang (2012). To fill the altitude gap between the uppermost and second uppermost plot, one more plot was established at an altitude of $3800 \mathrm{~m}$ where 34 mature trees were cored along a $10 \mathrm{~m}$ wide altitudinal belt (see Table 1).

The other gradient in an Abies georgei var. smithii Viguie and Gaussen on the southeastern Tibetan Plateau (SETP) was sampled during the summer of 2013. Four plots were sampled at altitudes ranging from 3900 to $4390 \mathrm{~m}$ (Fig. 1, Table 1). The two highest plots were located along the treeline (SE4390 and SE4360) and the two remaining plots were located at the medium (SE4140) and lower (SE3900) altitudes of this A. georgei forest (Fig. 1). For the treeline plots, increment cores were obtained from at least 30 trees within a belt 
Table 1. Information on the plots, tree-ring samples, and climate conditions along the latitudinal gradient in Finland and the altitudinal gradients on the southern Tibetan Plateau.

\begin{tabular}{|c|c|c|c|c|c|c|c|c|c|c|c|}
\hline Site & $\begin{array}{c}\text { Plot } \\
\text { no. }\end{array}$ & $\begin{array}{l}\text { Region } \\
\text { code }^{\mathrm{a}}\end{array}$ & $\begin{array}{r}\text { Latitude } \\
(\mathrm{N})\end{array}$ & $\begin{array}{r}\text { Longitude } \\
\text { (E) }\end{array}$ & $\begin{array}{r}\text { Altitude } \\
(\mathrm{m})\end{array}$ & $\begin{array}{r}\text { No. of } \\
\text { trees }\end{array}$ & $\begin{array}{r}\text { No. of } \\
\text { cores }\end{array}$ & $\mathrm{MSL}^{\mathrm{b}}$ & $\begin{array}{r}\mathrm{MAT}^{\mathrm{c}} \\
\left({ }^{\circ} \mathrm{C}\right)\end{array}$ & $\begin{array}{r}\mathrm{MAP}^{\mathrm{c}} \\
(\mathrm{mm})\end{array}$ & $\begin{array}{r}T_{\text {July }}{ }^{\mathrm{c}} \\
\left({ }^{\circ} \mathrm{C}\right)\end{array}$ \\
\hline \multicolumn{12}{|l|}{ Finland } \\
\hline Vuotso & 1 & NFIN & $68^{\circ} 13^{\prime}$ & $27^{\circ} 11^{\prime}$ & 300 & 9 & 18 & 163 & -1.77 & 483 & 11.1 \\
\hline Pokka & 2 & NFIN & $68^{\circ} 08^{\prime}$ & $25^{\circ} 43^{\prime}$ & 285 & 10 & 20 & 146 & -1.65 & 484 & 11.2 \\
\hline Pokka & 3 & NFIN & $68^{\circ} 03^{\prime}$ & $25^{\circ} 39^{\prime}$ & 295 & 11 & 21 & 152 & -0.35 & 543 & 11.2 \\
\hline Pallastunturi & 4 & NFIN & $68^{\circ} 02^{\prime}$ & $24^{\circ} 04^{\prime}$ & 410 & 11 & 11 & 211 & -0.94 & 519 & 11.0 \\
\hline Pallastunturi & 5 & NFIN & $68^{\circ} 00^{\prime}$ & $24^{\circ} 08^{\prime}$ & 370 & 11 & 11 & 180 & -0.7 & 519 & 11.2 \\
\hline Kittilä, Tieva & 6 & NFIN & $68^{\circ} 00^{\prime}$ & $25^{\circ} 43^{\prime}$ & 275 & 10 & 20 & 138 & -0.38 & 543 & 11.4 \\
\hline Vuotso & 7 & NFIN & $68^{\circ} 00^{\prime}$ & $26^{\circ} 55^{\prime}$ & 305 & 11 & 22 & 189 & -1.89 & 491 & 11.3 \\
\hline Pallasjärvi & 8 & NFIN & $67^{\circ} 59^{\prime}$ & $24^{\circ} 14^{\prime}$ & 330 & 11 & 11 & 67 & -1.74 & 486 & 11.3 \\
\hline Vuotso & 9 & NFIN & $67^{\circ} 59^{\prime}$ & $26^{\circ} 35^{\prime}$ & 270 & 10 & 19 & 148 & -1.5 & 488 & 11.5 \\
\hline Pallas & 10 & NFIN & $67^{\circ} 58^{\prime}$ & $24^{\circ} 05^{\prime}$ & 405 & 8 & 8 & 173 & -1.67 & 492 & 11.1 \\
\hline Kittilä, Kiistala & 11 & NFIN & $67^{\circ} 58^{\prime}$ & $25^{\circ} 39^{\prime}$ & 305 & 10 & 20 & 124 & -1.09 & 500 & 11.3 \\
\hline Soukkavaara & 12 & NFIN & $67^{\circ} 51^{\prime}$ & $24^{\circ} 51^{\prime}$ & 305 & 10 & 10 & 191 & -0.36 & 543 & 11.6 \\
\hline Jerisjärvi & 13 & NFIN & $67^{\circ} 50^{\prime}$ & $23^{\circ} 59^{\prime}$ & 335 & 9 & 9 & 153 & -1.57 & 487 & 11.5 \\
\hline Pomokaira & 14 & NFIN & $67^{\circ} 50^{\prime}$ & $26^{\circ} 25^{\prime}$ & 265 & 11 & 22 & 183 & -1.9 & 495 & 11.4 \\
\hline Kittilä, Saattopora & 15 & NFIN & $67^{\circ} 47^{\prime}$ & $24^{\circ} 21^{\prime}$ & 270 & 10 & 19 & 177 & -1.78 & 493 & 11.7 \\
\hline Kittilä, Kumputunturi & 16 & NFIN & $67^{\circ} 38^{\prime}$ & $25^{\circ} 32^{\prime}$ & 205 & 6 & 12 & 204 & -1.17 & 499 & 12.0 \\
\hline Sodankylä, Mosku & 17 & NFIN & $67^{\circ} 37^{\prime}$ & $27^{\circ} 11^{\prime}$ & 210 & 10 & 20 & 131 & -1.38 & 494 & 11.8 \\
\hline Kittilä, Tepsa & 18 & NFIN & $67^{\circ} 35^{\prime}$ & $25^{\circ} 32^{\prime}$ & 202 & 10 & 19 & 167 & -0.9 & 521 & 12.1 \\
\hline Ristonmännikkö & 19 & NFIN & $67^{\circ} 10^{\prime}$ & $26^{\circ} 19^{\prime}$ & 245 & 10 & 20 & 209 & -1.9 & 493 & 12.1 \\
\hline Niesi, Karhukuru & 20 & NFIN & $66^{\circ} 59^{\prime}$ & $25^{\circ} 54^{\prime}$ & 215 & 13 & 13 & 187 & -1.87 & 480 & 12.4 \\
\hline Niesi, Kunetti & 21 & NFIN & $66^{\circ} 59^{\prime}$ & $25^{\circ} 53^{\prime}$ & 270 & 13 & 13 & 258 & -0.9 & 521 & 12.2 \\
\hline Niesi, Kutuselkä & 22 & NFIN & $66^{\circ} 55^{\prime}$ & $25^{\circ} 52^{\prime}$ & 255 & 11 & 11 & 262 & 0.04 & 539 & 12.3 \\
\hline Niesi, Kutuselkä & 23 & NFIN & $66^{\circ} 55^{\prime}$ & $25^{\circ} 56^{\prime}$ & 275 & 13 & 13 & 170 & -2.14 & 481 & 12.3 \\
\hline Niesi, Turhapuro & 24 & NFIN & $66^{\circ} 55^{\prime}$ & $25^{\circ} 56^{\prime}$ & 275 & 10 & 20 & 149 & -1.89 & 482 & 12.3 \\
\hline Kivalo & 25 & NFIN & $66^{\circ} 19^{\prime}$ & $26^{\circ} 40^{\prime}$ & 285 & 11 & 11 & 241 & -2.07 & 478 & 12.5 \\
\hline Kivalo & 26 & NFIN & $66^{\circ} 19^{\prime}$ & $26^{\circ} 42^{\prime}$ & 240 & 10 & 20 & 202 & -2.27 & 477 & 12.7 \\
\hline Kivalo & 27 & NFIN & $66^{\circ} 18^{\prime}$ & $25^{\circ} 42^{\prime}$ & 240 & 10 & 20 & 190 & -0.56 & 543 & 12.7 \\
\hline Kivalo & 28 & NFIN & $66^{\circ} 18^{\prime}$ & $25^{\circ} 42^{\prime}$ & 250 & 9 & 9 & 169 & -0.39 & 543 & 12.6 \\
\hline Kivalo & 29 & NFIN & $66^{\circ} 18^{\prime}$ & $25^{\circ} 42^{\prime}$ & 245 & 12 & 12 & 192 & -0.81 & 521 & 12.7 \\
\hline Lamu, Mäsäjärvi & 30 & NFIN & $66^{\circ} 18^{\prime}$ & $25^{\circ} 31^{\prime}$ & 160 & 13 & 13 & 157 & -1.06 & 511 & 13.1 \\
\hline $\begin{array}{l}\text { Kivalo } \\
\text { King }\end{array}$ & 31 & NFIN & $66^{\circ} 18^{\prime}$ & $26^{\circ} 45^{\prime}$ & 315 & 10 & 20 & 173 & -0.65 & 544 & 12.4 \\
\hline Kivalo & 32 & NFIN & $66^{\circ} 18^{\prime}$ & $26^{\circ} 43^{\prime}$ & 310 & 10 & 20 & 199 & -0.64 & 544 & 12.4 \\
\hline Pyhä-Häkki & 33 & SFIN & $62^{\circ} 50^{\prime}$ & $25^{\circ} 29^{\prime}$ & 175 & 10 & 20 & 185 & $\begin{array}{r}2.4 \\
2.4\end{array}$ & 630 & 14.2 \\
\hline Pyhä-Häkki & 34 & SFIN & $62^{\circ} 49^{\prime}$ & $25^{\circ} 29^{\prime}$ & 162 & 10 & 20 & 86 & 2.4 & 630 & 14.2 \\
\hline Pyhä-Häkki & 35 & SFIN & $62^{\circ} 49^{\prime}$ & $25^{\circ} 29^{\prime}$ & 162 & 10 & 20 & 124 & 2.4 & 630 & 14.2 \\
\hline Pyhä-Häkki & 36 & SFIN & $62^{\circ} 49^{\prime}$ & $25^{\circ} 29^{\prime}$ & 166 & 10 & 20 & 96 & 2.4 & 630 & 14.2 \\
\hline Pyhä-Häkki & 37 & SFIN & $62^{\circ} 49^{\prime}$ & $25^{\circ} 29^{\prime}$ & 166 & 10 & 20 & 134 & 2.4 & 630 & 14.2 \\
\hline Pyhä-Häkki & 38 & SFIN & $62^{\circ} 49^{\prime}$ & $25^{\circ} 29^{\prime}$ & 162 & 9 & 18 & 126 & 2.4 & 630 & 14.2 \\
\hline Pyhä-Häkki & 39 & SFIN & $62^{\circ} 49^{\prime}$ & $25^{\circ} 29^{\prime}$ & 172 & 10 & 20 & 120 & 2.4 & 630 & 14.2 \\
\hline Pyhä-Häkki & 40 & SFIN & $62^{\circ} 49^{\prime}$ & $25^{\circ} 29^{\prime}$ & 172 & 9 & 18 & 92 & 2.4 & 630 & 14.2 \\
\hline Tammela & 41 & SFIN & $60^{\circ} 44^{\prime}$ & $23^{\circ} 43^{\prime}$ & 110 & 10 & 20 & 82 & 4.29 & 635 & 15.1 \\
\hline Tammela & 42 & SFIN & $60^{\circ} 43^{\prime}$ & $23^{\circ} 41^{\prime}$ & 110 & 10 & 20 & 80 & 4.29 & 636 & 15.1 \\
\hline Tammela & 43 & SFIN & $60^{\circ} 41^{\prime}$ & $23^{\circ} 50^{\prime}$ & 120 & 10 & 20 & 126 & 4.26 & 640 & 15.1 \\
\hline Tammela & 44 & SFIN & $60^{\circ} 41^{\prime}$ & $23^{\circ} 49^{\prime}$ & 120 & 10 & 20 & 122 & 4.26 & 640 & 15.1 \\
\hline Tammela & 45 & SFIN & $60^{\circ} 41^{\prime}$ & $23^{\circ} 50^{\prime}$ & 120 & 10 & 20 & 108 & 4.27 & 641 & 15.1 \\
\hline Tammela & 46 & SFIN & $60^{\circ} 40^{\prime}$ & $23^{\circ} 52^{\prime}$ & 115 & 10 & 20 & 172 & 4.3 & 642 & 15.1 \\
\hline Tammela & $\begin{array}{l}40 \\
47\end{array}$ & SFIN & $60^{\circ} 39^{\prime}$ & $23^{\circ} 52^{\prime}$ & 115 & 10 & 20 & 147 & 4.31 & 643 & 15.1 \\
\hline Tammela & 48 & SFIN & $60^{\circ} 39^{\prime}$ & $23^{\circ} 53^{\prime}$ & 115 & 10 & 20 & 171 & 4.31 & 643 & 15.1 \\
\hline \multicolumn{12}{|c|}{ Southern Tibetan Plateau } \\
\hline SE4390 & 49 & SETP & $29^{\circ} 39^{\prime}$ & $94^{\circ} 43^{\prime}$ & 4390 & 52 & 52 & 146 & -3.09 & 786 & 6.4 \\
\hline SE4360 & 50 & SETP & $29^{\circ} 36^{\prime}$ & $94^{\circ} 36^{\prime}$ & 4360 & 41 & 41 & 153 & -2.83 & 786 & 6.6 \\
\hline SE4140 & 51 & SETP & $29^{\circ} 39^{\prime}$ & $94^{\circ} 43^{\prime}$ & 4140 & 31 & 31 & 195 & -0.97 & 786 & 8.0 \\
\hline SE3900 & 52 & SETP & $29^{\circ} 39^{\prime}$ & $94^{\circ} 43^{\prime}$ & 3900 & 30 & 30 & 160 & 1.06 & 786 & 9.5 \\
\hline SC3920 & 53 & SCTP & $27^{\circ} 50^{\prime}$ & $87^{\circ} 28^{\prime}$ & 3920 & 50 & 50 & 119 & 3.05 & 1113 & 12.0 \\
\hline SC3800 & 54 & SCTP & $27^{\circ} 50^{\prime}$ & $87^{\circ} 28^{\prime}$ & 3800 & 32 & 32 & 141 & 3.67 & 1113 & 12.6 \\
\hline SC3700 & 55 & SCTP & $27^{\circ} 50^{\prime}$ & $87^{\circ} 28^{\prime}$ & 3700 & 45 & 45 & 109 & 4.18 & 1113 & 13.1 \\
\hline SC 3520 & 56 & SCTP & $27^{\circ} 50^{\prime}$ & $87^{\circ} 28^{\prime}$ & 3520 & 83 & 83 & 93 & 5.11 & 1113 & 14.0 \\
\hline SC 3410 & 57 & SCTP & $27^{\circ} 50^{\prime}$ & $87^{\circ} 27^{\prime}$ & 3410 & 37 & 37 & 74 & 5.67 & 1113 & 14.6 \\
\hline
\end{tabular}




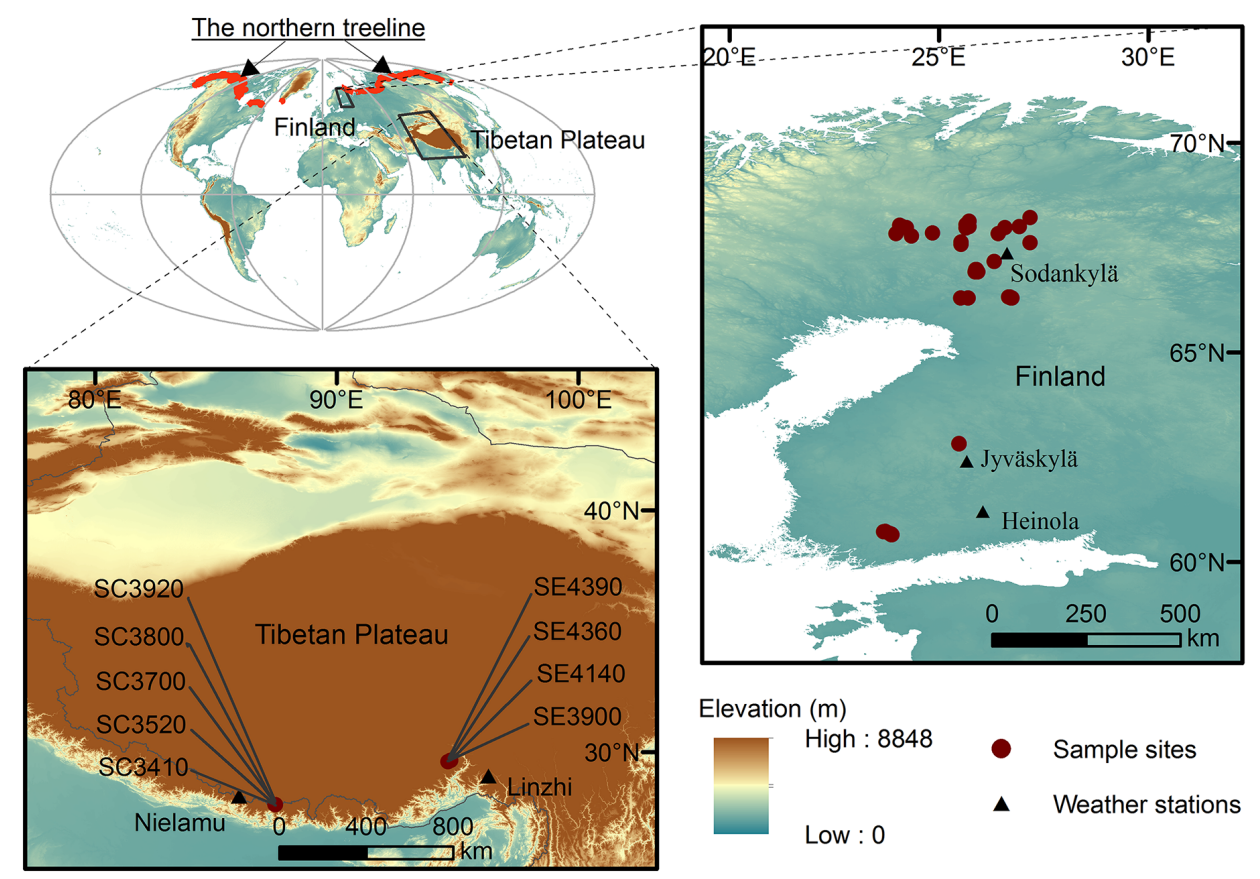

Figure 1. Location map of the sample plots and weather stations in Finland and on the Tibetan Plateau.

of $30 \mathrm{~m}$ in width along the treeline, and these were cored for each plot. The lengths of the sampled treeline belts were 260 and $380 \mathrm{~m}$ for SE4390 and SE4360, respectively, according to the stand density. For each of the remaining two altitudinal plots, using a single rectangular plot over a relatively small areal range (due to larger stand densities) might reflect very specific conditions, such as particular microclimates and landforms of the plot. To increase the representativeness of forest stands, six random groups of $A$. george $i$ were sampled. Each group consisted of a central tree and the four nearest trees in different compass directions around the central tree.

\subsection{Tree-ring data sets}

Ring widths were visually cross-dated and measured to an accuracy of at least $0.01 \mathrm{~mm}$ and cross-dating was verified via COFECHA software (Holmes, 1983). For the Finnish data set, a total of 820 tree-ring width series from $48 P$. abies stands were successfully cross-dated. For the Tibetan Plateau data set, 401 tree-ring width series from nine Abies stands (247 trees from five stands on the SCTP and 154 trees from four stands on the SETP) were successfully cross-dated. Mean segment length (MSL) ranged from 67 to $262 \mathrm{a}$ in the Finnish data set, and from 74 to $195 \mathrm{a}$ in the Tibetan Plateau data set (Table 1).

To remove age-related trends, the ring-width series were detrended with a spline function with a $50 \%$ frequency response cutoff at 30 years using the ARSTAN software (Cook and Peters, 1981). Ring-width indices (RWIs) were subsequently calculated as the ratio between measured and esti- mated values. Mean site chronologies were calculated for each plot from the RWIs using the robust bi-weight mean (Cook, 1985).

\subsection{Climate data sets}

Daily climatic data (mean temperature and precipitation sum) were obtained from the Finnish Meteorological Institute for the Finnish gradient and from the China Meteorological Data Service Centre (http://data.cma.cn/) for the gradients of the Tibetan Plateau. Weather stations with a long measurement series were used to cover as much of the tree-ring chronologies as possible. We used the Sodankylä $\left(26^{\circ} 37^{\prime} \mathrm{E}, 67^{\circ} 21^{\prime} \mathrm{N} ; 179 \mathrm{~m}\right.$ a.s.l.), Jyväskylä $\left(62^{\circ} 24^{\prime} \mathrm{N}, 25^{\circ} 40^{\prime} \mathrm{E} ; 139 \mathrm{~m}\right.$ a.s.l. $)$, and Heinola $\left(61^{\circ} 12^{\prime} \mathrm{N}\right.$, $26^{\circ} 3^{\prime} \mathrm{E}$; $92 \mathrm{~m}$ a.s.1.) weather stations from the northern, central, and southern parts of Finland and the weather stations Nielamu $\left(28^{\circ} 11^{\prime} \mathrm{N}, 85^{\circ} 58^{\prime} \mathrm{E}\right.$; $3810 \mathrm{~m}$ a.s.l. $)$ and Linzhi $\left(29^{\circ} 40^{\prime} \mathrm{N}, 94^{\circ} 20^{\prime} \mathrm{E} ; 2992 \mathrm{~m}\right.$ a.s.1.) from the SCTP and the SETP data, respectively (Fig. 2).

To ensure comparability of the latitudinal and the altitudinal gradients, we analysed the relationships of tree growth and climatic variation on a gradient of mean temperature of the warmest month (July). For the Finnish data set, we derived the mean July temperature for each site from the interpolated climate data set at a spatial resolution of $10 \times 10 \mathrm{~km}$ (Venäläinen et al., 2005). We also calculated the mean July temperature for each plot of the Tibetan Plateau data set. July temperatures were obtained based on the altitude differences between the plots and weather station and monthly 

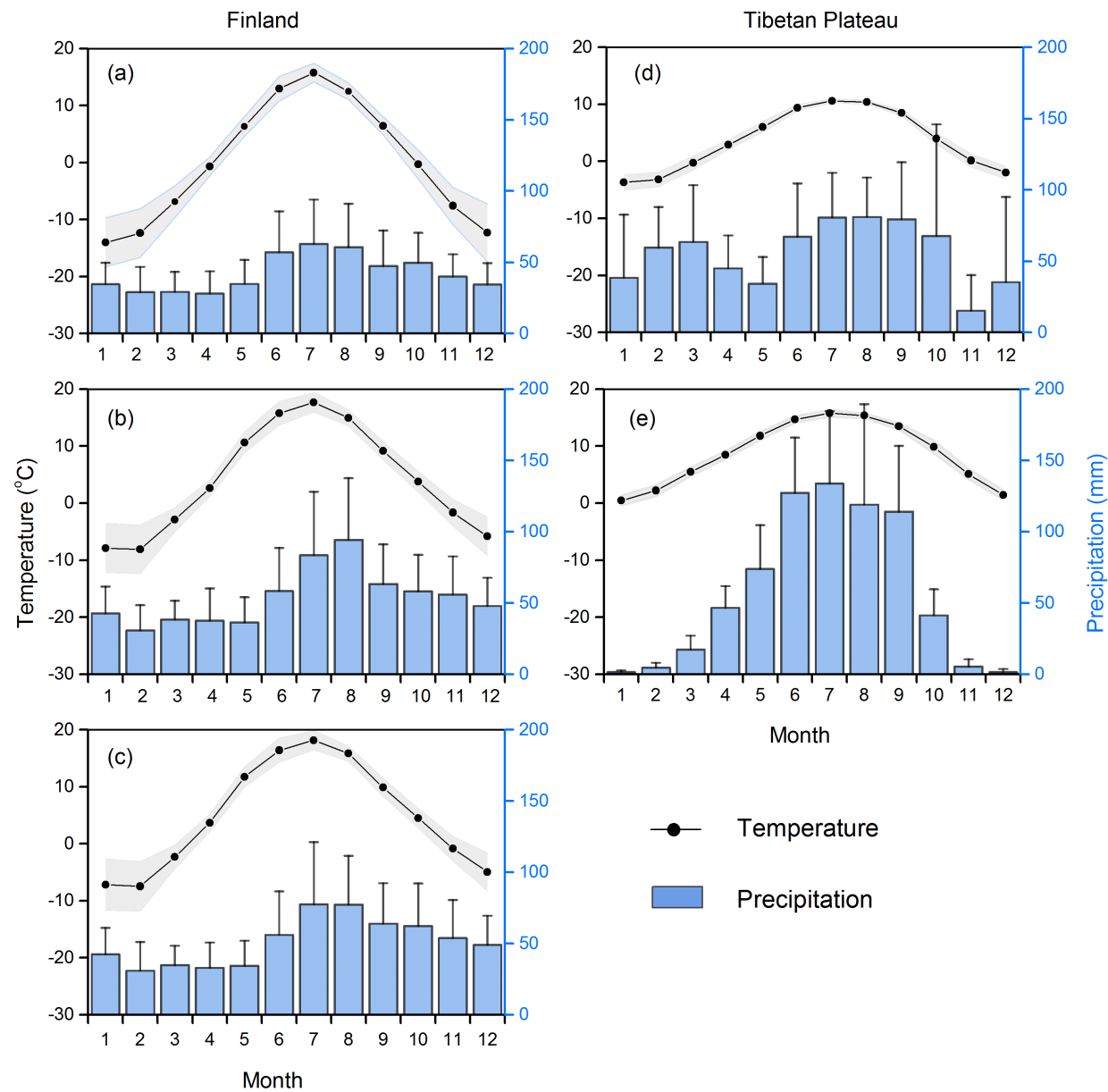

Figure 2. Monthly mean temperature and precipitation sums at the weather stations used in the study include the following: Heinola (a), Jyväskylä (b), and Sodankylä (c) in Finland and Linzhi (d) and Nielamu (e) on the Tibetan Plateau. The shaded area around the marked lines and the error bars of the columns are the 1 SD (standard deviation) of the monthly mean temperatures and the monthly precipitation sum over the recording period, respectively.

temperature lapse rates were defined for the SCTP by Kattel et al. (2013) and for the SETP by Kattel et al. (2015). In contrast to temperatures, the altitudinal changes in precipitation on the Tibetan Plateau strongly varied between different parts of the region. The precipitation increased by $14.3 \mathrm{~mm}$ on the SCTP, while it decreased by $21.7 \mathrm{~mm}$ on the SETP as altitude increased $100 \mathrm{~m}$; however, a substantial variability existed within each region (Lu et al., 2007).

To depict the potential drought limitations on tree growth, we calculated the daily vapour pressure deficit (VPD) based on vapour pressure $(V)$ and relative air pressure $(\mathrm{RH})$ records, using Eq. (1) (Allen et al., 1998):

$\mathrm{VPD}=V \times \frac{1-\mathrm{RH}}{\mathrm{RH}}$.

Since absolute-value changes would not affect the results of the correlation analyses between tree-ring width indices and climate variables, the precipitation and VPD were not adjusted for each plot on the Tibetan Plateau. Given that tree growth was only weakly limited by precipitation on the latitudinal gradient (Mäkinen et al., 2000), VPD was not calculated for the Finnish sites.

\subsection{Statistical methods}

Mean and standard deviation (SD) of ring widths, as well as mean inter-series correlation (Rbar) and first-order autocorrelation (AR1) of the increment index series were calculated for each plot. Mean inter-series correlations measure the synchrony of radial growth variations among trees within a forest stand and first-order autocorrelation is a correlation between subsequent increment indices (Fritts, 1976).

To study the relationship between climate variables and ring-width indices, we calculated Pearson product-moment correlation coefficients between the RWIs with temperature and precipitation for both the current year and the previous year. Instead of using monthly means, mean temperature and precipitation sums were calculated in moving time windows 
of 31 days by moving the period forward at a resolution of 1 day. Correlations were calculated between the RWIs and climate variables for all possible 31-day windows from the start of the previous May to the end of the August of the growth year. The correlation periods were 1938-1997 and 1968-2006 for both the Finnish and the Tibetan Plateau gradients, respectively.

The critical time periods of temperature and precipitation were identified for each plot based on the best correlation with mean RWI chronologies. To illustrate and emphasize potential regional differences in climatic signals among the seasons, we defined four seasons (previous growing season: May to August of the previous year; previous post-growing season: September to December of the previous year; current pre-growing season: January to April of the growth year; current growing season: May to August of the growth year) and separately chose the most correlated periods within each season to arrive at a more general picture of the growth-climate relationships. The correlation analysis was conducted using the statistical software R 3.23 (R Core Team, 2015).

\section{Results}

The means and SD of stand level ring widths increased towards the south for Finland and towards lower elevations for the Tibetan Plateau (Fig. 3). Similarly, mean inter-series correlations (Rbar) decreased towards the warm end of the latitudinal or altitudinal gradients; however, they did not reach a $5 \%$ significance level. In addition, weak increasing trends were observed for first-order autocorrelations towards the cold ends of both gradients (Lyu et al., 2017).

During the current growing season, the positive correlation peaks between radial growth and temperatures were typically significant at high latitudes (northern Finland) and high altitudes (plots 49-50 of the SETP and 53-54 of the SCTP), whereas, the correlations were either weaker or nonsignificant for lower-altitude or lower-latitude plots (Figs. 4 and 5d). In addition, the RWIs from high latitudes and altitudes negatively correlated with early summer (MayJune) temperatures, but the correlations were weaker or nonsignificant for plots at the warmer end of the latitudinal gradient (Figs. 4 and 5). On the Tibetan Plateau, these negative correlations were accompanied by positive correlations with precipitation (Figs. $4 \mathrm{~g}$ and $5 \mathrm{~h}$ ) and negative correlations with VPD (Fig. 4i and j) during the early part of the growing season, especially for the two lower-altitude plots of the SCTP.

During the current pre-growing season, significant negative correlations between the RWIs and February temperatures were found for most Finnish plots (Figs. 4 and 5g). These negative correlation peaks showed a latitudinal pattern, with stronger correlations for northern plots (Fig. 5g). On the Tibetan Plateau, the correlations between the RWIs and winter temperatures were mainly non-significant (Figs. 4 and $5 \mathrm{~g}$ ), although negative correlation peaks with late winter temperatures occurred on one low-elevation plot in the SETP gradient.

During the previous post-growing season, significant positive correlations were found between RWIs and temperatures around November for most Finland sites (Fig. 4) without clear latitudinal trends (Fig. 5b). Furthermore, positive correlations also occurred at the Tibetan sites (Fig. 4), but these only reached a $5 \%$ significance level at the two lower sites of the SETP and two sites of the SCTP (Fig. 5b). Moreover, significant and negative correlations with temperatures in late October were observed at the two lower sites of the SCTP.

During the previous growing season, positive correlations between temperatures and the RWI chronologies were found in both Finnish and Tibetan gradients (Fig. 4); however, these lacked clear patterns in the magnitudes of the correlation peaks (Fig. 5b). Negative correlations with previous growing season temperatures were found for many of the plots on the Tibetan Plateau and in southern Finland, but not for high-latitude plots in Finland (Figs. 4 and 5e). On the Tibetan Plateau, the magnitude of the negative correlation peaks between RWIs and temperatures during the previous growing season did not reveal an altitudinal trend (Fig. 5e).

The timing of the highest correlation varied between the plots throughout all seasons (Fig. 6). While in some cases time windows with the highest correlation did not differ notably (e.g. Tibetan Plateau plots in Fig. 6b and d). In other cases, time windows with the highest correlations were spread throughout the whole season (e.g. Finnish plots in Fig. 6a and b). The Finnish plots seemed to show a larger variability in this respect.

The time windows with the highest correlations between the RWI chronologies and climate variables were mostly found outside of calendar months (Fig. 6). A correlation analysis with monthly climate data resulted in weaker correlation coefficients and fewer significant correlations than if daily climate data were used (Figs. 5 and 7). For instance, tree growth on both high-altitude plots (SC3920 and SC3800) on the SCTP significantly correlated with temperatures during the current growing season (Fig. 5d), but this association was not detected when calendar months were used (Fig. 7d).

\section{Discussion}

\subsection{Radial growth variation}

Our results confirmed that ring widths were thinner at the cold ends of both latitudinal and altitudinal gradients than at the warm ends. Moreover, radial-growth variations (as indicated by SD) also decreased with increasing latitude and altitude. Interestingly, slightly declining trends were detected for mean inter-series correlation (Rbar) towards the warm end of the gradients. This pattern corresponded with the expectation that tree growth in general is more sensitive to environmental changes towards the harsher end of an environmental gradi- 


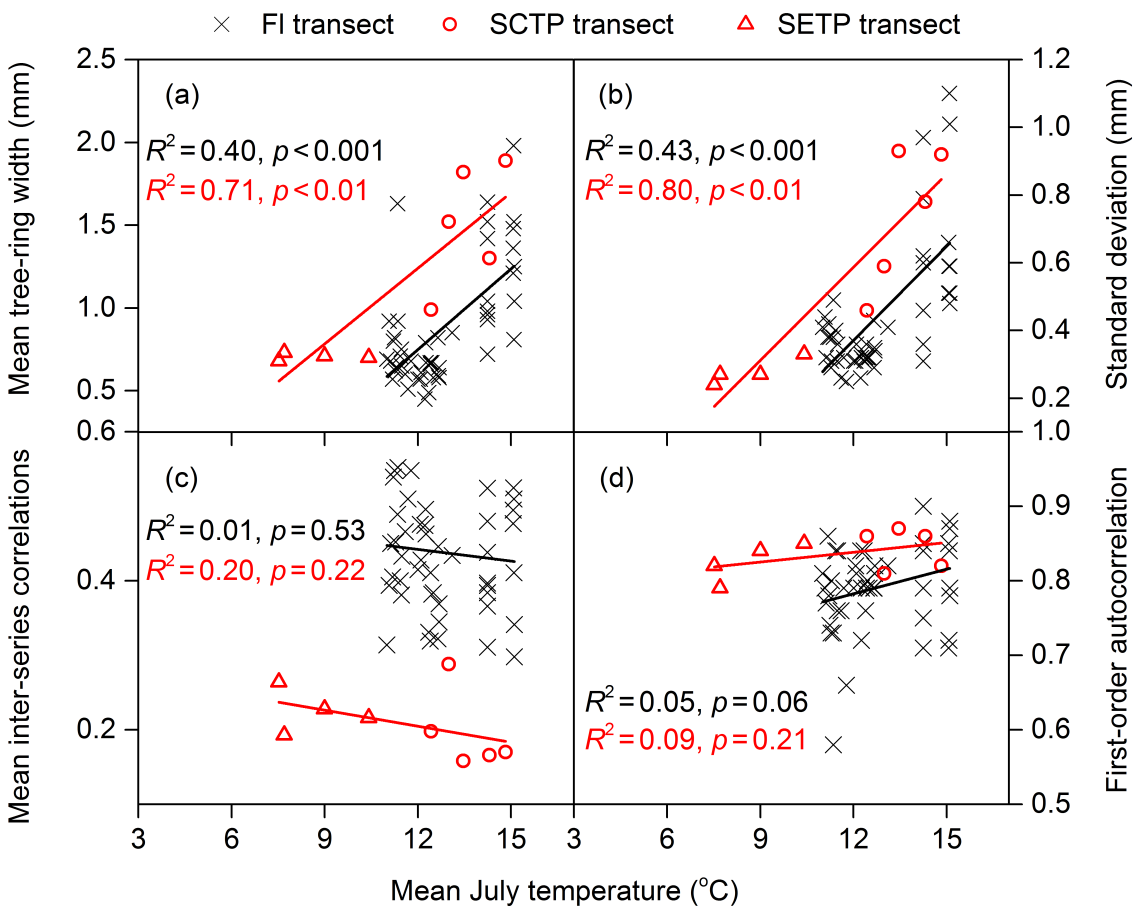

Figure 3. Stand level statistics of raw tree-ring widths along the latitudinal gradient in Finland (FI) and the altitudinal gradients on the Tibetan Plateau (TP). The lines are linear regression lines. The black colour marks the data for the latitudinal gradient, and the red denotes the data for the altitudinal gradients.

ent and will respond similarly to the common driver (Fritts, 1976). However, the pattern that inter-tree synchrony of radial growth decreased with increasing altitude was also found in a recent study on the southern Tibetan Plateau (Lyu et al., 2016a). The underlying mechanism accountable for this pattern remains largely unknown. We suggest that the temperature gradients might be influenced by local factors, such as drought and plant-plant interactions. Local factors such as stand density and landform could shape diversified habitats with varying limiting conditions beyond temperatures. Previous studies showed tree growth on the Tibetan Plateau to be affected by drought conditions (Liang et al., 2014) as well as by competition from both trees and shrubs (Lyu et al., 2016b; Liang et al., 2016).

\subsection{Climate signals of tree radial growth}

Our results suggest that positive correlations between tree radial growth and growing season temperatures are stronger towards the cold end of the gradients. This suggestion is supported by earlier studies on latitudinal and altitudinal gradients (Mäkinen et al., 2003; Andreassen et al., 2006; Shen et al., 2016). The observed negative correlations with temperatures during May and June also showed a gradient pattern, with significant correlations mainly occurring on highaltitude and high-latitude plots (Figs. 4 and 5h). In the SETP gradient, this negative correlation was accompanied by a positive correlation with precipitation (Fig. 5f), thus indicating a drought limitation of tree growth. The negative correlations between the RWI with VPD further confirmed this suggested drought limitation on tree radial growth (Fig. 4), which is also supported by a previous study in the area (Lv and Zhang, 2012). However, the RWIs of the Finnish plots were not positively correlated with precipitation during the time periods of negative correlations with temperatures of the early growing season. This suggests that these negative correlations were not related to a lack of moisture in Finland. Indeed, droughts during spring are rare in Finland due to abundant moisture from the melting snow. Consequently, similar temperature correlation patterns in the early summer for the latitudinal and altitudinal gradients are caused by different underlying mechanisms.

The correlation peaks of temperature and tree growth during the previous post-growing season were found to be significant and positive throughout all gradients, but with relatively weaker strength compared to correlations of the current growing season. This could be related to carbohydrate production during autumn being stored and used for growth in the following growing season (Rammig et al., 2015). Low temperatures were often reported to affect tree growth through bud damage and frost desiccation (Hawkins, 1993). Increasing temperatures may cause less damage to leaves and buds and thus be less limiting for subsequent radial growth (Liang et al., 2006; Fan et al., 2009). However, positive correlations in our results with temperature from November to De- 

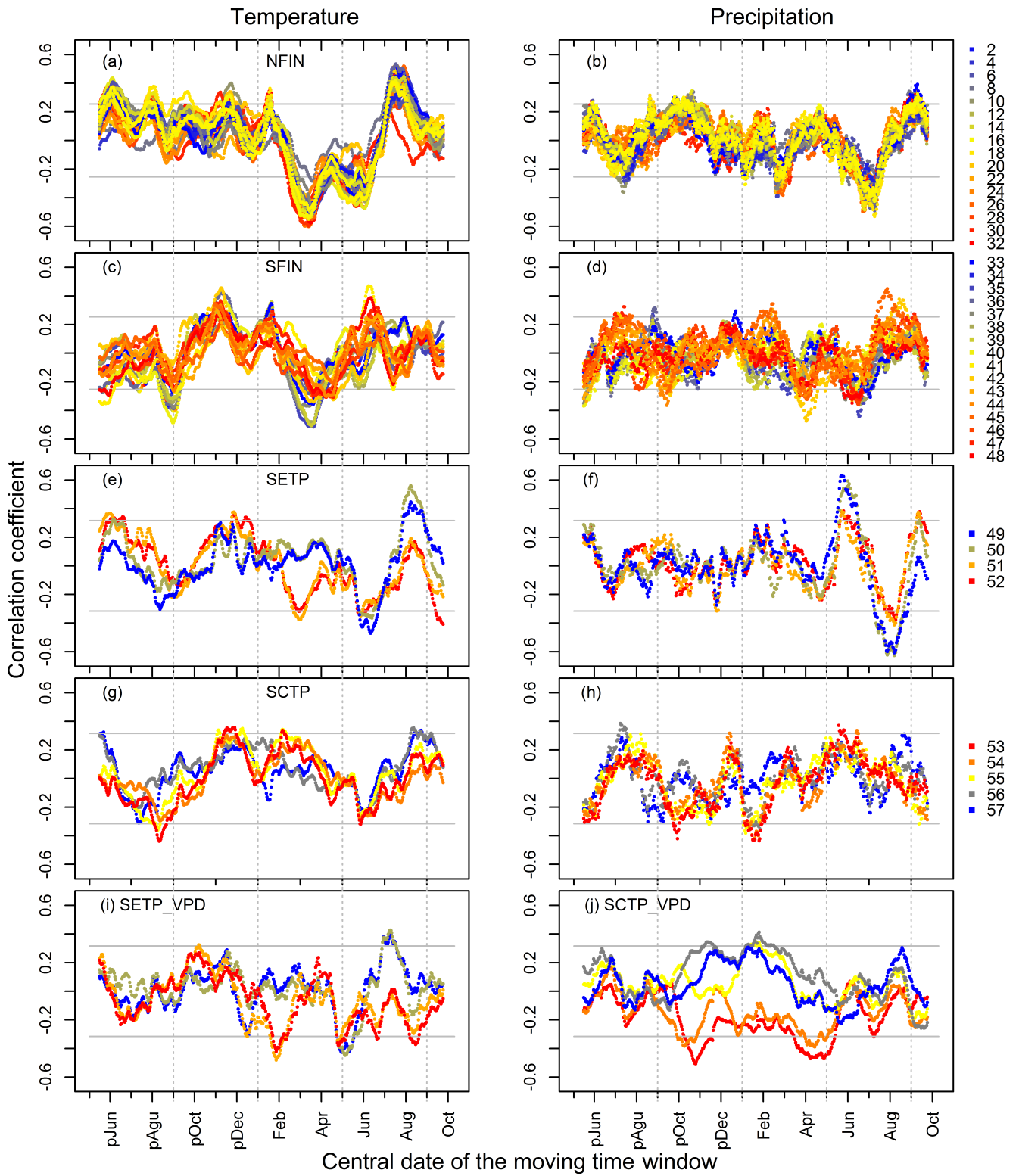

Figure 4. Correlation coefficients between the ring-width index chronologies (separate sub-figures for each region, and separate colours for each plot) and mean temperature (left column apart from the last row), precipitation sum (right column apart from the last row) and vapour pressure deficit (VPD) (the bottom row, for the SCTP and SETP) in moving time windows of 31 days. The $x$ axis is the central day of the time window used in calculating the climate variables, with the first day of each month marked by ticks. The plot numbers are consistent with Table 1. Note that the colour gradient legend for sub-panels (a)-(b) is by two sites. The correlation periods for the Finnish and the Tibetan subsets are 1938-1997 and 1968-2006, respectively. The grey horizontal lines denote the 5\% significance levels.

cember were also found for Finland, when light levels were low for photosynthesis and trees were likely to be in winter dormancy (Repo, 1992; Beuker et al., 1998). The underlying mechanism still remains unclear.

Our results demonstrate the effect of February temperatures on radial growth in the latitudinal gradient of Finland, but not for altitudinal gradients. Significant and negative correlations were found across the whole latitudinal gradient, particularly on the northern plots. Previous studies in these high-latitude regions revealed similar results for $P$. abies forests (Miina, 2000; Mäkinen et al., 2003; Andreassen et al., 2006). Reduced growth during years with mild winters could be related to the timing of spring activation. Early activation from dormancy during warm winters may lead to a net carbon loss if respiration losses exceed the photosynthetic production due to low light levels (Skre and Nes, 1996; Linkosalo et al., 2014). Early activation in spring also increases the risk of frost damage (Cannell and Smith, 1986; Hannerz, 

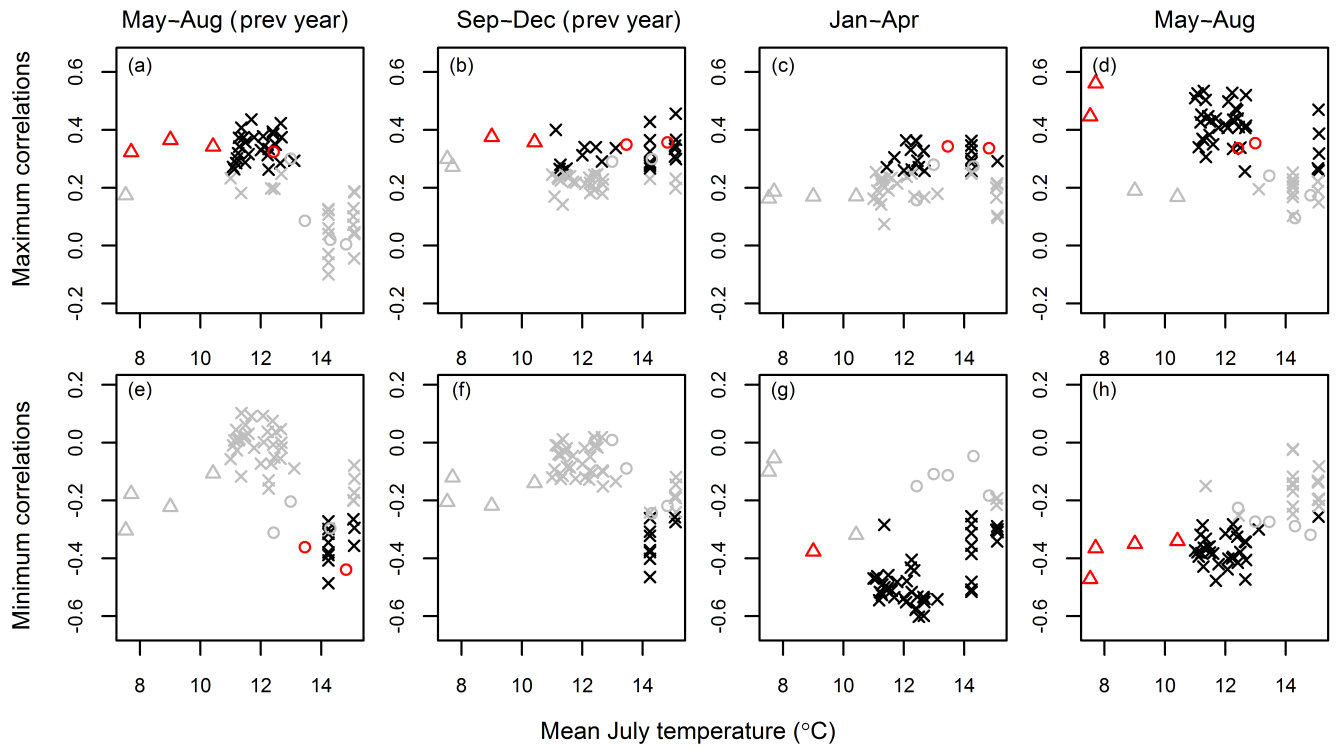

Figure 5. The magnitude of the maximum (largest positive) (a-d) and minimum (largest negative) (e-h) correlations between the RWIs and temperature against the mean July temperature of each plot. The correlations are shown separately in four seasons, so that the central dates of the time window used for calculating the climate variables is located in the (1) previous growing season (previous year May to August, first column), (2) previous post-growing season (previous year September to December, second column), (3) current pre-growing season (growth year January to April, third column), and (4) current growing season (growth year May to August, fourth column). The black X's denote the plots in Finland; the red circles and triangles denote the plots of the altitudinal gradients on the south-central Tibetan Plateau (SCTP) and southeastern Tibetan Plateau (SETP), respectively. The grey colour indicates correlations not significant at the $5 \%$ level.
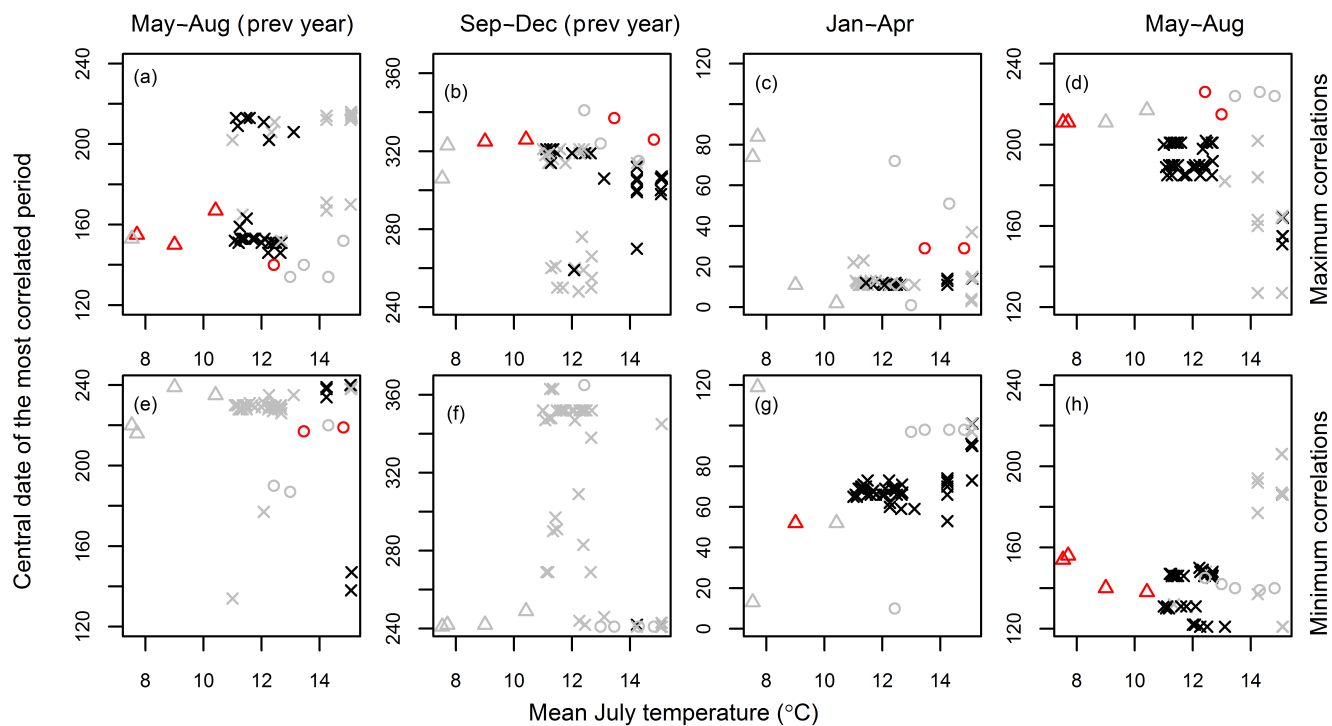

Figure 6. The central dates of the 31-day time windows with maximum (largest positive) (a-d) and minimum (largest negative) (e-h) correlations between the RWIs and temperature in Fig. 4. The black X mark denotes the plots in Finland and the plots on the south-central Tibetan Plateau (SCTP) are marked with red circles and on the southeastern Tibetan Plateau (SETP) with red triangles. The grey colour indicates correlations not significant at the $5 \%$ level.

1994). In contrast, the correlations between the RWIs and winter temperatures were mainly non-significant on the Tibetan Plateau. Only one low-altitude plot of the SETP gradi- ent had a significant negative correlation between the RWIs and temperature around March.

Latitudinal and altitudinal gradients shared a similar decreasing trend in temperature during the current growing sea- 

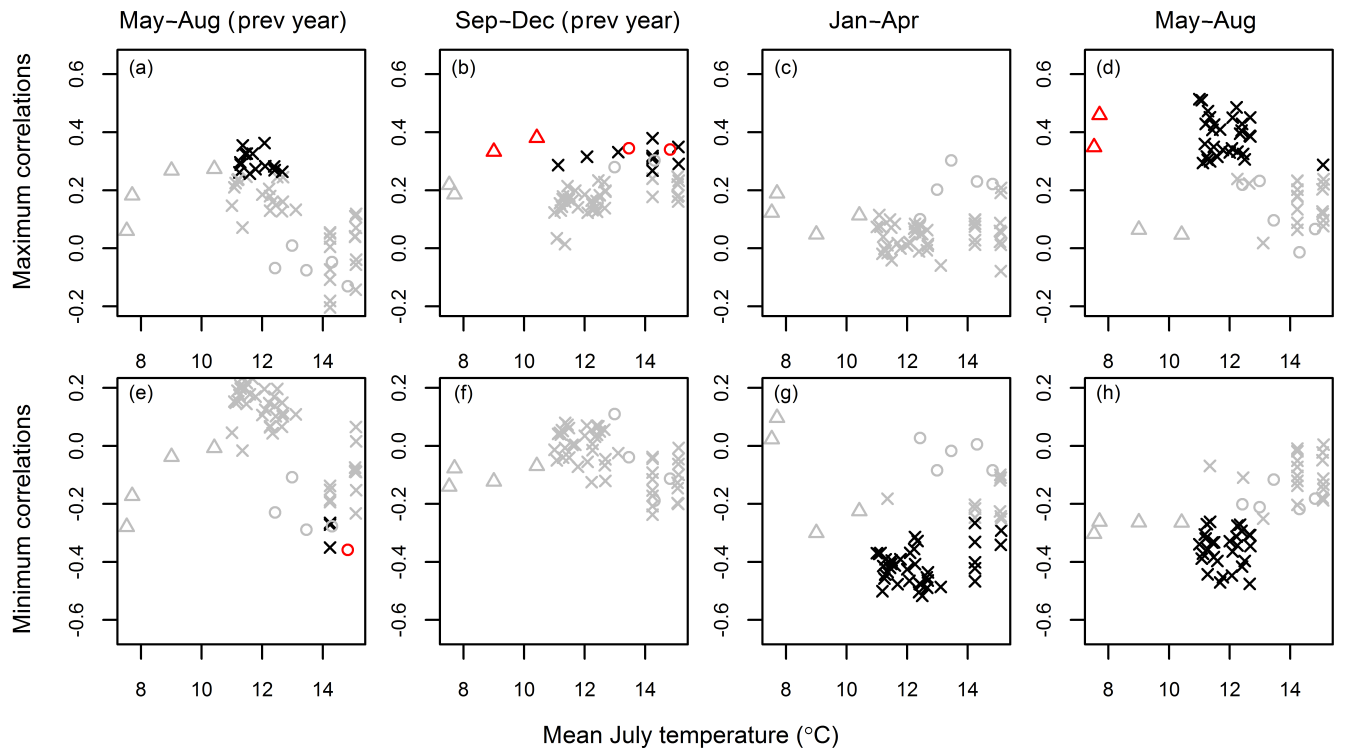

Figure 7. The magnitude of the maximum (largest positive) (a-d) and minimum (largest negative) (e-h) correlations between the RWIs and monthly mean temperatures in different seasons (columns) against the mean July temperature of each plot. The black X's denote the plots in Finland and the plots on the south-central Tibetan Plateau (SCTP) are marked with red circles and on the southeastern Tibetan Plateau (SETP) with red triangles. The grey colour indicates correlations not significant at the $5 \%$ level.

son, but many other factors, such as precipitation and light availability, were not necessarily consistent between gradients (Körner, 2007; Jump et al., 2009). Despite avoiding drought-prone locations in the selection of the study sites for both the Finnish and Tibetan data sets, moisture conditions still differed between Finland and the Tibetan Plateau. For instance, negative correlations with temperature, combined with positive correlations with precipitation during early summer, indicate moisture limitation of tree growth on the Tibetan sites. The moisture limitation on tree growth was found for lower-altitude plots on the SCTP in our previous study (Lv and Zhang, 2012). Compared to the Finnish plots, the Tibetan plots might have higher evapotranspiration due to higher solar radiance (Leuschner, 2000), particularly at lower altitudes due to higher temperatures.

\subsection{The critical time windows for climatic influence on tree growth}

Our results support the hypothesis that the timing of the most influential time window during which climatic conditions influence tree growth changes along both latitudinal and altitudinal gradients. In the southernmost sites of the latitudinal gradient, time windows with the strongest positive correlations between the RWIs and current growing season temperature (May-August) were about 1 month ahead of the northernmost sites, while no obvious trend could be detected for altitudinal gradients. However, the strongest negative correlation between the RWIs and temperature during the current growing season occurred about 15 days earlier at the lowest- altitude site on the SETP than at the treeline sites, indicating likely alleviation of moisture limitation with increasing altitude.

Our results demonstrate that the use of daily-resolution climate data can provide more details in the study of tree growth-climate relationships. The timing of tree growth changes along altitudinal and latitudinal gradients (Rossi et al., 2007; Henttonen et al., 2009; Jyske et al., 2014) and therefore the timing of the most influential period is bound to change. In northern Finland, the onset of the growing season is approximately mid-June (Jyske et al., 2014), while the growing season starts in late May in southern Finland (Henttonen et al., 2009). Our results show that the timing of the most influential time period for tree growth is bounded by the onset of the growing seasons and is gradually delayed from south to north along the latitudinal gradient. Due to the critical nature of the early part of the growing season for the volume growth of trees (Cuny et al., 2015), an earlier start of the growing season means an earlier critical period of radial growth along the gradients. The strength of the relationship between tree growth and climatic variables could be underestimated due to a failure in identifying the most influential periods outside of calendar months. Usage of daily-resolution climate data is thus recommended in future studies that investigate growth-climate relationships along environmental gradients.

The sliding window length of 31 days used in this study was the result of a trade-off between stiffness (longer time window) and noisiness (shorter time window). If a small time window (e.g. below 10 days) was used, noisy correlation pat- 
terns were introduced due to year-by-year variations in climate conditions. However, an overly long time window is not recommended either, as it fails to detect the most critical period of radial growth.

\section{Conclusions}

Our results support the hypothesis that the change in the growth-climate relationship is similar along both latitudinal and altitudinal gradients, particularly for the effects of growing season temperature on growth. In addition to temperature, other factors such as moisture availability affect growth variation, consequently adding uncertainties to a comparison of temperature gradients. Therefore, a combined analysis that incorporates the effects of these gradient-type-related features with temperature trends merits further investigation.

We demonstrated that the use of daily-resolution climatic data reveals more accurate information about the climatic signals in tree-ring data than monthly data. The critical time windows for climatic effects on radial growth occurred earlier at lower latitudes and altitudes than at the cold ends of the gradients. Therefore, the use of daily climatic data may disclose gradient patterns that could not be detected if monthly climate data were used.

Data availability. All data resulting from this study are available from the authors upon request (qbzhang@ibcas.ac.cn for the Tibetan subset; harri.makinen@luke.fi for the Finnish subset).

Competing interests. The authors declare that they have no conflict of interest.

Acknowledgements. This study was supported by the National Natural Science Foundation of China (nos. 31361130339, 31330015, and 31300409) and by grants from the Academy of Finland (nos. 257641 and 265504). The climatic data were obtained from the China Meteorological Data Service Centre and the Finnish Meteorological Institute.

Edited by: Trevor Keenan

Reviewed by: two anonymous referees

\section{References}

Allen, R. G., Pereira L. S., Raes D., and Smith, M.: Crop Evapotranspiration-guidelines for Computing Crop Water Requirements, Food and Agriculture Organization of United Nation, Rome, Italy, 1998.

Andreassen, K., Solberg, S., Tveito, O. E., and Lystad, S. L.: Regional differences in climatic responses of Norway spruce (Picea abies L. Karst) growth in Norway, Forest Ecol. Manag., 222, 211-221, https://doi.org/10.1016/j.foreco.2005.10.029, 2006.
Blois, J. L., Williams, J. W., Fitzpatrick, M. C., Jackson, S. T., and Ferrier, S.: Space can substitute for time in predicting climatechange effects on biodiversity, P. Natl. Acad. Sci. USA, 110, 9374-9379, https://doi.org/10.1073/pnas.1220228110, 2013.

Briffa, K. R., Osborn, T. J., Schweingruber, F. H., Jones, P. D., Shiyatov, S. G., and Vaganov, E. A.: Tree-ring width and density data around the Northern Hemisphere: Part 1, local and regional climate signals, Holocene, 12, 737-757, https://doi.org/10.1191/0959683602hl587rp, 2002.

Cannell, M. G. R. and Smith, R. I.: Climatic Warming, Spring Budburst and Forest Damage on Trees, J. Appl. Ecol., 23, 177-191, https://doi.org/10.2307/2403090, 1986.

Cook, E. R.: A time series analysis approach to tree-ring standardization, Dissertation, University of Arizona, USA, 1985.

Cook, E. R. and Peters, K.: The smoothing spline: a new approach to standardizing forest interior tree-ring width series for dendroclimatic studies, Tree-Ring Bulletin, 41, 45-53, 1981.

Cuny, H. E., Rathgeber, C. B. K., Frank, D., Fonti, P., Mäkinen, H., Prislan, P., Rossi, S., del Castillo, E., Campelo, F., Vavrčík, H., Camarero, J., Bryukhanova, M. V., Jyske, T., Gričar, J., Gryc, J., Luis, M., Vieira, J., Čufar, K., Kirdyanov, A. V., Oberhuber, W., Treml, V., Huang, J. G., Li, X., Swidrak, I., Deslauriers, A., Liang, E., Nöjd, P., Gruber, A., Nabais, C., Morin, H., Krause, C., King, G., and Fournier, M.: Wood biomass production lags stem-girth increase by over one month in coniferous forests, Nature Plants, 1, 15160, https://doi.org/10.1038/nplants.2015.160, 2015.

Di Filippo, A., Biondi, F., Čufar, K., De Luis, M., Grabner, M., Maugeri, M., Presutti Saba, E., Schirone, B., and Piovesan, G.: Bioclimatology of beech (Fagus sylvatica L.) in the Eastern Alps: spatial and altitudinal climatic signals identified through a tree-ring network, J Biogeogr., 34, 1873-1892, https://doi.org/10.1111/j.1365-2699.2007.01747.x, 2007.

Fan, Z. and Thomas, A.: Spatiotemporal variability of reference evapotranspiration and its contributing climatic factors in Yunnan Province, SW China, 1961-2004, Climatic Change, 116, 309325, https://doi.org/10.1007/s10584-012-0479-4, 2013.

Fan, Z., Bräuning, A., Cao, K., and Zhu, S.: Growth-climate responses of high-elevation conifers in the central Hengduan Mountains, southwestern China, Forest Ecol. Manag., 258, 306313, https://doi.org/10.1016/j.foreco.2009.04.017, 2009.

Fritts, H. C.: Tree Rings and Climate, Academic Press, London, 1976.

Hannerz, M.: Predicting the risk of frost occurrence after budburst of Norway spruce in Sweden, Silva Fenn, 28, 243-249, https://doi.org/10.14214/sf.a9175, 1994.

Hawkins, B. J.: Photoperiod and night frost influence the frost hardiness of Chamaecyparisnootkatensis clones, Can. J. Forest Res. 23, 1408-1414, https://doi.org/10.1139/x93-178, 1993.

Henttonen, H., Kanninen, M., Nygren, M., and Ojansuu, R.: The Maturation of Pinus sylvestris Seeds in Relation to Temperature Climate in Northern Finland, Scand. J. Forest Res., 1, 243-249, 1986.

Henttonen, H. M., Mäkinen, H., and Nöjd, P.: Seasonal dynamics of the radial increment of Scots pine and Norway spruce in the southern and middle boreal zones in Finland, Can. J. Forest Res., 39, 606-618, https://doi.org/10.1139/X08-203, 2009.

Henttonen, H. M., Mäkinen, H., Heiskanen, J., Peltoniemi, M., Laurén, A., and Hordo, M.: Response of radial incre- 
ment variation of Scots pine to temperature, precipitation and soil water content along a latitudinal gradient across Finland and Estonia, Agr. Forest Meteorol., 198-199, 294-308, https://doi.org/10.1016/j.agrformet.2014.09.004, 2014.

Holmes, R. L.: Computer-assisted quality control in tree-ring data and measurement, Tree-Ring Bulletin, 43, 69-78, 1983.

Hordo, M., Henttonen, H. M., Mäkinen, H., Helama, S., and Kiviste, A.: Annual Growth Variation of Scots Pine in Estonia and Finland, Balt. For., 17, 35-49, 2011.

Jobbágy, E. G. and Jackson, R. B.: Global controls of forest line elevation in the northern and southern hemispheres, Global. Ecol. Biogeogr., 9, 253-268, https://doi.org/10.1046/j.13652699.2000.00162.x, 2000.

Jump, A. S., Mátyás, C., and Peñuelas, J.: The altitude-for-latitude disparity in the range retractions of woody species, Trends Ecol. Evol., 24, 694-701, https://doi.org/10.1016/j.tree.2009.06.007, 2009.

Jyske, T., Mäkinen, H., Kalliokoski, T., and Nöjd, P.: Intra-annual tracheid production of Norway spruce and Scots pine across a latitudinal gradient in Finland, Agr. Forest Meteorol., 194, 241254, https://doi.org/10.1016/j.agrformet.2014.04.015, 2014.

Kattel, D. B., Yao, T., Yang, K., Tian, L., Yang, G., and Joswiak, D.: Temperature lapse rate in complex mountain terrain on the southern slope of the central Himalayas, Theor. Appl. Climatol., 113, 671-682, https://doi.org/10.1007/s00704-012-0816-6, 2013.

Kattel, D. B., Yao, T., Yang, W., Gao, Y., and Tian, L.: Comparison of temperature lapse rates from the northern to the southern slopes of the Himalayas, Int. J. Climatol., 35, 4431-4443, https://doi.org/10.1002/joc.4297, 2015.

Kim, E. and Siccama, T. G.: The influence of temperature and soil moisture on the radial growth of northern hardwood tree species at Hubbard Brook Experimental Forest, New Hampshire, USA, in: Proceedings, International Symposium on Ecological Aspects of Tree-Ring Analysis., edited by: Jacoby, G. C. and Hornbeck, J. W., U.S. Dep. Energy Publ. CONF-8608144-26-37, 26-37, 1987.

Körner, C.: A re-assessment of high elevation treeline positions and their explanation, Oecologia, 115, 445-459, https://doi.org/10.1007/s004420050540, 1998.

Körner, C.: The use of "altitude" in ecological research, Trends Ecol. Evol., 22, 569-574, https://doi.org/10.1016/j.tree.2007.09.006, 2007.

Korpela, M., Nöjd, P., Hollmén, J., Mäkinen, H., Sulkava, M., and Hari, P.: Photosynthesis, temperature and radial growth of Scots pine in northern Finland: identifying the influential time intervals, Trees, 25, 323-332, https://doi.org/10.1007/s00468-0100508-8, 2011.

Leuschner, C.: Are high elevations in tropical mountains arid environments for plants?, Ecology, 81, 1425-1436, 2000.

Liang, E., Dawadi, B., Pederson, N., and Eckstein, D.: Is the growth of birch at the upper timberline in the Himalayas limited by moisture or by temperature?, Ecology, 95, 2453-2465, https://doi.org/10.1890/13-1904.1, 2014.

Liang, E., Wang, Y., Piao, S., Lu, X., Camarero, J. J., Zhu, H., Zhu, L., Ellison, A. M., Ciais, P., and Peñuelas, J.: Species interactions slow warming-induced upward shifts of treelines on the Tibetan Plateau, P. Natl. Acad. Sci., 113, 4380-4385, https://doi.org/10.1073/pnas.1520582113, 2016.

Liang, E. Y., Shao, X. M., Eckstein, D., Huang, L., and Liu, X. H.: Topography- and species-dependent growth responses of Sabina przewalskii and Picea crassifolia to climate on the northeast Tibetan Plateau, Forest Ecol. Manag., 236, 268-277, 2006.

Linkosalo, T., Heikkinen, J., Pulkkinen, P., and Mäkipää, R.: Fluorescence measurements show stronger cold inhibition of photosynthetic light reactions in Scots pine compared to Norway spruce as well as during spring compared to autumn, Frontiers in Plant Science, 5 264, https://doi.org/10.3389/fpls.2014.00264, 2014.

Loehle, C.: Height growth rate tradeoffs determine northern and southern range limits for trees, J. Biogeogr., 25, 735-742, https://doi.org/10.1046/j.1365-2699.1998.2540735.x, 1998.

Loehle, C., Idso, C., and Bently Wigley, T.: Physiological and ecological factors influencing recent trends in United States forest health responses to climate change, Forest Ecol. Manag., 363, 179-189, https://doi.org/10.1016/j.foreco.2015.12.042, 2016.

Lu, C., Wang, L., Xie, G., and Leng, Y.: Altitude Effect of Precipitation and Spatial Distribution of Qinghai-Tibetan Plateau, J. Mountain Sci., 25, 655-663, https://doi.org/10.3969/j.issn.10082786.2007.06.003, 2007.

Lv, L.-X. and Zhang, Q.-B.: Asynchronous recruitment history of Abies spectabilis along an altitudinal gradient in the Mt. Everest region, J. Plant Ecol., 5, 147-156, https://doi.org/10.1093/jpe/rtr016, 2012.

Lyu, L., Deng, X., and Zhang, Q.-B.: Elevation Pattern in Growth Coherency on the Southeastern Tibetan Plateau, PLoS One, 11, e0163201, https://doi.org/10.1371/journal.pone.0163201, 2016a.

Lyu, L., Zhang, Q.-B., Deng, X., and Mäkinen, H.: Fine-scale distribution of treeline trees and the nurse plant facilitation on the eastern Tibetan Plateau, Ecol Indic, 66, 251-258, https://doi.org/10.1016/j.ecolind.2016.01.041, 2016b.

Lyu, L., Suvanto, S., Nöjd, P., Henttonen, H. M., Mäkinen, H., and Zhang, Q.-B.: Dataset for BG-2016-559 (Tree growth and its climate signal along latitudinal and altitudinal gradients: comparison of tree rings between Finland and the Tibetan Plateau), https://doi.org/10.6084/m9.figshare.4522928.v4, 2017.

Mäkinen, H., Nöjd, P., and Mielikäinen, K.: Climatic signal in annual growth variation of Norway spruce (Picea abies) along a transect from central Finland to the Arctic timberline, Can. J. Forest Res., 30, 769-777, https://doi.org/10.1139/x00-005, 2000.

Mäkinen, H., Nöjd, P., and Mielikäinen, K.: Climatic signal in annual growth variation in damaged and healthy stands of Norway spruce [Picea abies (L.) Karst.] in southern Finland, Trees, 15, 177-185, https://doi.org/10.1007/s004680100089, 2001.

Mäkinen, H., Nöjd, P., Kahle, H.-P., Neumann, U., Tveite, B., Mielikäinen, K., Röhle, H., and Spiecker, H.: Radial growth variation of Norway spruce (Picea abies (L.) Karst.) across latitudinal and altitudinal gradients in central and northern Europe, Forest Ecol. Manag., 171, 243-259, https://doi.org/10.1016/S03781127(01)00786-1, 2002.

Mäkinen, H., Nöjd, P., Kahle, H.-P., Neumann, U., Tveite, B., Mielikäinen, K., Röhle, H., and Spiecker, H.: Large-scale climatic variability and radial increment variation of Picea abies (L.) Karst. in central and northern Europe, Trees, 17, 173-184, https://doi.org/10.1007/s00468-002-0220-4, 2003.

Miina, J.: Dependence of tree-ring, earlywood and latewood indices of Scots pine and Norway spruce on climatic factors in eastern Finland, Ecol. Model., 132, 259-273, https://doi.org/10.1016/S0304-3800(00)00296-9, 2000. 
Rammig, A., Wiedermann, M., Donges, J. F., Babst, F., von Bloh, W., Frank, D., Thonicke, K., and Mahecha, M. D.: Coincidences of climate extremes and anomalous vegetation responses: comparing tree ring patterns to simulated productivity, Biogeosciences, 12, 373-385, https://doi.org/10.5194/bg-12-373-2015, 2015.

R Core Team: R: A language and environment for statistical computing, R Foundation for Statistical Computing. Vienna, Austria, available at: http://www.R-project.org, 2016

Repo, T.: Seasonal changes of frost hardiness in Picea abies and Pinus sylvestris in Finland, Can. J. Forest Res., 22, 1949-1957, https://doi.org/10.1139/x92-254, 1992.

Rossi, S., Deslauriers, A., Anfodillo, T., and Carraro, V.: Evidence of threshold temperatures for xylogenesis in conifers at high altitudes, Oecologia, 152, 1-12, https://doi.org/10.1007/s00442006-0625-7, 2007.

Shen, C., Wang, L., and Li, M.: The altitudinal variability and temporal instability of the climate-tree-ring growth relationships for Changbai larch (Larix olgensis Henry) in the Changbai mountains area, Jilin, Northeastern China, Trees, 30, 901-912, https://doi.org/10.1007/s00468-015-1330-0, 2016.
Skre, O. and Nes, K.: Combined effects if elevated winter temperatures and $\mathrm{CO}_{2}$ on Norway spruce seedlings, Silva Fenn, 30, 135 $143,1996$.

Stevens, G. C.: The Elevational Gradient in Altitudinal Range: An Extension of Rapoport's Latitudinal Rule to Altitude, Am. Nat., 140, 893-911, https://doi.org/10.1086/285447, 1992.

Vaganov, E. A., Hughes, M. K., Kirdyanov, A. V., Schweingruber, F. H., and Silkin, P. P.: Influence of snowfall and melt timing on tree growth in subarctic Eurasia, Nature, 400, 149-151, https://doi.org/10.1038/22087, 1999.

Venäläinen, A., Tuomenvirta, H., Pirinen, P., and Drebs, A.: A Basic Finnish Climate Data Set 1961-2000-description and Illustrations. Reports 2005:5, Finnish Meteorological Institute, Helsinki, p. 27., 2005.

Wettstein, J. J., Littell, J. S., Wallace, J. M., and Gedalof, Z. E.: Coherent region-, species-, and frequency-dependent local climate signals in Northern Hemisphere tree-ring widths, J. Climate, 24, 5998-6012, https://doi.org/10.1175/2011JCLI3822.1, 2011. 